\title{
NEW $L^{q}$ INEQUALITIES FOR POLYNOMIALS
}

\author{
AbDul AZIZ AND NisAR AHMED RATHER
}

Abstract. In this paper we establish some new $L^{q}$ inequalities for polynomials which generalize and refine some results of Szegö, Zygmund, De Bruijn and others.

Mathematics subject classification (1991): Primary 26D05, 30D15, Secondary 41A17.

Key words and phrases: Polynomials, Zygmund's inequality, $L^{q}$ inequalities.

\section{REFERENCES}

[1] V. V. ARESTOV, On integral inequalities for trigonometric polynomials and their derivatives, Izv. Akad. Nauk. SSSR., Ser. Mat. 45 (1981), 3-22 [in Russian], English translation: Math. USSR - Izv. 18 (1982), 1-17.

[2] A. AZIZ, A new proof and a generalization of a theorem of De Bruijn, Proc. Amer. Math. Soc. 106 (2) (1989), 345-350.

[3] Growth of polynomials whose zeros are within or outside a circle, Bull. Austral. Math. Soc. 35 (1987), 247-256.

[4] A. AZIZ AND Q. M. DAwood, Inequalities for a polynomial and its derivative, J. Approx. Theory $\mathbf{5 4}$ (1988), 306-313.

[5] A. AZIZ AND N. A. RATHER, $L^{p}$ inequalities for polynomials, Glasnik matematički 32 (51) (1997), 39-43.

[6] T. N. Chan And M. A. MaliK, On Erdös-Lax theorem, Proc. Indian Acad. Sci. 92 (1983), 191-193.

[7] N. G. DE BRUIJN, Inequalities concerning polynomials in the complex domain, Nederl. Akad, Wetensch. Proc. 50 (1947), 1265-1272: Indag. Math. 9 (1947), 591-598.

[8] K. K. DEWAN, Inequalities for a polynomial and its derivative II, J. Math. Anal. Appl. 190 (1995), 625-629.

[9] C. Frappier, Q. I. RAHMAn AND St. Ruscheweyh, New inequalities for polynomials, Trans. Amer. Math. Soc. 288 (1985), 69-99.

[10] N. K. GoviL, Some inequalities for derivative of polynomials, J. Approx. Theory 66 (1991), 29-35.

[11] N. K. GovIL AND Q. I. RAHMAN, Functions of exponential type not vanishing in a half-plane and related polynomials, Trans. Amer. Math. Soc. 137 (1969), 501-517.

[12] P. D. LAX, Proof of a conjecture of P. Erdös on the derivative of a polynomial, Bull. Amer. Math. Soc. 50 (1944), 509-513.

[13] M. A. MaLIK, On the derivative of a polynomial, J. London. Math. Soc 1 (1969), 57-80.

[14] G. V. Milovanović, D. S. Mitrinović AND TH. Rassias, Topics in polynomials: extremal properties, inequalities, zeros, World Scientific Publishing Co., Singapore, 1994.

[15] G. Pólya And G. SzEgÖ, Problems and theorems in analysis, Vol. I, Springer-Verlag, New York, 1972.

[16] M. A. QAZI, On the maximum modulus of polynomials, Proc. Amer. Math. Soc. 115 (1992).

[17] W. W. Rogosinski, Extremum problems for polynomials and trigonometrical polynomials, J. London Math. Soc. 29 (1954), 259-275.

[18] A. C. SChAEFFER, Inequalities of A. Markoff and S. Bernstein for polynomials and related functions, Bull. Amer. Math. Soc. 47 (1941), 565-579.

[19] G. SzEGÖ, Über einen Satz des Herrn Serge Bernstein, Schriften Koigsberger Gelehrten Gesellschaft 5 (1928), 59-70.

[20] Bemerkungen zu einem Satz von J. H, Grace Über die wurzeln algebraischer Gleichungen, Math. Z. 13 (1922), 28-55. 
[21] A. Zygmund, A remark on conjugate series, Proc. London Math. Soc. (2) 34 (1932), 392-400. [22] , Two notes on inequalities, J. Math. and Phys. 21 (1942), 117-123. 